\title{
El museo (en el) impreso. Un acercamiento al Museo de cuadros de costumbres $y$ variedades*
}

THE MUSEUM WITHIN THE PRINTED (MUSEUM). AN APPROACH TO THE MUSEO DE CUADROS DE COSTUMBRES Y VARIEDADES

O MUSEU (NEL) IMPRESSO. UMA ABORDAGEM AO MUSEO DE CUADROS DE COSTUMBRES Y VARIEDADES

\section{Diana Galindo Cruz**}

Cuadernos de Música, Artes Visuales y Artes Escénicas

/ Volumen 10 - Número 2 / julio - diciembre de 2015

/ ISSN 1794-6670/ Bogotá, D.C., Colombia / pp. 107-130

Fecha de recepción: 15 de julio de 2015 | Fecha de aceptación: 29 de septiembre de 2015 | Disponible en línea: 18 de diciembre de 2015. Encuentre este artículo en http://cuadernosmusicayartes.javeriana.edu.co/ doi: 10.11144/Javeriana.mavae10-2.miam

*Artículo de investigación. Hace parte del Trabajo de grado titulado "Un lugar en el borde, museología y escritura", presentado para optar al título de Magíster en Museología y Gestión del Patrimonio, de la Universidad Nacional de Colombia.

**Magíster en Museología y Gestión del Patrimonio de la Universidad Nacional de Colombia, vinculada a la Biblioteca Nacional de Colombia. 


\section{Resumen}

El presente artículo muestra a los "museos impresos" (publicaciones de carácter enciclopédico y misceláneo producidas entre los siglos XVI y XIX) como un caso particular en el desarrollo de las instituciones museísticas. A partir del estudio del $\mathrm{Mu}$ seo de cuadros de costumbres y variedades, publicación colombiana editada en 1866 por la tertulia El Mosaico, se analiza cómo los museos impresos funcionaron durante el siglo XIX latinoamericano como artefactos modernos de construcción de un sentido nacional mediante la elaboración escrita de un acervo patrimonial. Estos "museos impresos" hacían uso de gestos representacionales guiados por principios heredados de la llustración, y tenían objetivos educativos, políticos y económicos, como muestra del coleccionismo al servicio de agentes representativos del Estado en formación.

Palabras clave: museos impresos; coleccionismo; costumbrismo; siglo XIX; nación

\begin{abstract}
This paper studies the "printed museums" (miscellaneous and encyclopedic publications produced between the sixteenth and nineteenth centuries) as a particular case in the evolution of the museum and its related institutions. From readings of the Museo de cuadros de costumbres y variedades, a Colombian publication done in 1866 by the members of the literary group EI Mosaico, we analyze how printed museums worked in nineteenth century Latin America as modern artifacts used to build the national sentiment recording in writings the national patrimony. These "printed museums" used representational gestures guided by principles inherited of the Enlightenment and had political, economic and educational purposes, since they were an example of private collecting at the service of representative agents of the stillforming State.
\end{abstract}

Keywords: printed museums; collecting; costumbrismo; nineteenth century; nation

\section{Resumo}

O presente artigo apresenta os "museus impressos" (publicações de caráter enciclopédico e variado produzidas entre os séculos XVI y XIX) como caso particular no desenvolvimento das instituições museísticas. Começando pelo estudo do Museo de Cuadros de costumbres y variedades, publicação colombiana editada em 1866 pela tertúlia El Mosaico, analisa-se como os museus impressos funcionaram durante o século XIX latino-americano como artefatos modernos de construção de um sentido nacional, por meio da elaboração textual de um acervo patrimonial, desde os gestos representacionais dirigidos pelos princípios herdados da Ilustração, e com objetivos educativos, políticos e econômicos, como dá conta o colecionismo ao serviço de agentes representativos do Estado em formação.

Palavras chave: museus impressos; colecionismo; costumbrismo; século XIX; nação 
Vengan pues los escritores decentes y de buen gusto, a deleitar nuestra sociedad que no acepta ya cuadros pintados con mazamorra, sino con bellos y apacibles colores, y sobre todo, con fidelidad y exactitud.

José Caicedo Rojas, El Mosaico, 1859

El origen ya no es lo que se cuenta, sino la actividad multiforme y murmurante de producir el texto y de producir la sociedad como texto. El "progreso" es de tipo escriturario.

Michel de Certeau, La invención de lo cotidiano, 2000

\section{UN RÉGIMEN DE LO VISUAL}

El desarrollo del museo como institución, y el establecimiento de definiciones oficiales del concepto, ${ }^{1}$ han sido fruto de la evolución de prácticas que con el paso del tiempo han dado como resultado la actual configuración del patrimonio cultural, su uso y valoración. Un ejemplo de ello es el coleccionismo que actualmente hace parte del imaginario de la gestión museísti$\mathrm{ca}$, pero que como actividad tiene un origen distinto al del museo propiamente dicho. Mientras que la práctica de agrupar objetos respecto a valores atribuidos a una idea puede rastrearse en los rituales funerarios de las culturas precolombinas, así como en el antiguo Egipto y diversas culturas ancestrales, el museo no estuvo asociado en un inicio al acopio y exhibición de objetos, a lo que frecuentemente se alude con el término de museion. ${ }^{2}$

Aunque en el siglo XVII el primer lexicógrafo español, Sebastián de Covarrubias, continúa definiendo al museo como el lugar consagrado a las Musas, se hace evidente un cambio en el discurso. El primer museo que se podría denominar como público (en cuanto a que altera las restricciones de género y clase en la admisión), el Ashmolean de la Universidad de Oxford, abre sus puertas en 1683, y constituye un indicio del paso a la modernidad. Con el afán del coleccionismo propio de la curiosidad científica, la concepción de museo parte del museion como lugar donde podían realizarse diversas actividades de carácter científico, artístico y literario, al énfasis en la acumulación; el museo entra entonces al régimen de lo visual; por supuesto, sin dejar de lado las actividades de estudio e investigación, lo que también configura al museo en su espacio.

En este sentido, y en cuanto al 'museo' como término, Paula Findlen afirma que, en esta época,

(...) desde un punto de vista filológico, su peculiar expansión permite su cruce y fusión con

las categorías filosóficas de biblioteca, thesaurus, ${ }^{3}$ y pandechion, ${ }^{4}$ con construcciones visuales como cornucopia ${ }^{5}$ y gazophylacium, ${ }^{6}$ y construcciones espaciales como studio, casino, cabinet/ gabinetto, gallería, y theatro. (Findlen, 2006, p. 23)

Entidades representativas del entorno cultural europeo del momento, y que muestran la fuerza del 'museo' para ingresar en otros ámbitos discursivos. De otro lado, durante el Renacimiento, 
(...) la fusión del studio con el museo se va perfilando espacialmente. Los coleccionistas humanistas necesitan un espacio bien definido donde poder actuar y el museo era un principio localizable que circunscribía un espacio donde podían realizarse una serie de actividades intelectuales. (Hernández, 2006, p. 25)

Ambas unidades (studio y museo) son concebidas como construcciones intelectuales dentro de círculos sociales específicos, y distan por ello de la denominación de museo público, como ocurre con el Ashmolean.

La sociedad de los siglos XVI y XVII se caracteriza, entre otras cosas, por la valoración del coleccionismo. Los círculos sociales a los cuales respondía el museo del momento basaban su especificidad en la pertenencia a una comunidad letrada, en la posesión de un código, en la adquisición del conocimiento mediante la observación, el análisis tangible y el registro pormenorizado del objeto de estudio. El nuevo orden de lo visual eleva la conciencia y desarrolla la introspección:

Una consecuencia de la nueva declaración visual perfectamente repetible fue la ciencia moderna.

La observación precisa no comienza con la ciencia moderna. Durante siglos, siempre ha sido esen-

cial para la supervivencia entre, por ejemplo, cazadores y artesanos de muchos tipos. Lo distintivo

de la ciencia moderna es la unión de la observación y la articulación verbal exactas: descripciones

precisas de objetos y procesos complejos, cuidadosamente observados. (Ong, 1987, p. 126)

La conciencia que se articula con la oralidad prioriza la acción más que la observación de las características visuales de los elementos, ya se trate de objetos, lugares o personas, y su consecuente descripción y clasificación es un producto plenamente escritural. Entonces, si la conciencia visual afecta la ciencia, afecta además al museo moderno, o más bien, posibilita su existencia.

Es el canon moderno el que combina el afán coleccionista con la definición de museo, debido al predominio del campo visual. En lo que Luis Gerardo Morales (reseñando el trabajo de la historiadora Paula Findlen) denomina como "la invención de la curiosidad moderna" se entrecruza el coleccionismo museográfico y la ciencia en el tejido de la escritura. Ahora que el mundo se sitúa en la hoja en blanco, sea esta papel o gabinete de la Europa mediterránea del $\mathrm{XVI}$, es posible desentrañarlo, organizarlo:

En la Era del "Ojo curioso", el museo de curiosidades proclama la omnipotencia del ojo (de la vista), órgano necesario para la observación razonada de lo que se percibe como un mundo objetivo externo al sujeto observador mejor conocido como 'el visitante'. (Morales, 2006, p. 32)

Los gabinetes que durante el siglo XVI representan la naturaleza desmitificada, requieren y se fundan en la observación curiosa, ajena a la veneración ciega; no obstante, hacia el siglo $X V I I$, hay un giro que vincula la observación de la naturaleza al desciframiento del orden divino presente en ella, que inserta aún más al museo en el campo visual. La Voz ya no se escucha, sino que se disecciona y categoriza. Conforme avanza la definición del espacio privado en la modernidad, avanza también la idea de quién puede o no ingresar a él, y con qué fin. Aunque Morales afirma que

(...) la experiencia de la lectura de un libro es distinta, por supuesto, a la de un museo. En el recinto museístico la lectura de las colecciones descansa en una sociabilidad que se comporta como un auténtico espectáculo cívico observable conforme a una determinada ideología de la visibilidad. (2006, pp. 33-34) 
Estamos situados en el mismo régimen de la escritura que determina prácticas sociales de observación similares. La conciencia de un visitante-lector específico también articula el resultado final de exposición: con el tiempo surgen tratados que recomiendan la adecuada disposición de las colecciones en el espacio, así como su registro y catalogación; también es evidente cómo para el libro surge una conciencia editorial, un ejemplo de ello es la creación de índices y carátulas, que se van transformando progresivamente con el fin de facilitar la lectura, concretando los títulos de las obras mediante la concentración en el aspecto de la palabra, más que en su sonido. ${ }^{7}$

Es posible hablar de colección cuando existe un sentido agrupador y clasificatorio que parte de la taxonomía, entendida como principio organizador, pero más que nada, de un "querer dirigir" la mirada pública. Cohesión, clasificación y esfera pública permiten el encuentro del museo con el impreso:

Los objetos museográficos aparecerán en el Renacimiento y en la Contrarreforma barroca en medio de un mar de textos impresos. Como dice Findlen: "los coleccionistas siempre deseaban saber la etimología del nombre y las circunstancias de su producción. De esta manera, el artefacto se localizaba dentro de un canon tanto literario como científico, definido tanto por Ovidio y Horacio, como por Aristóteles y Plinio. El ingreso de un nuevo artefacto ocasionaba como era de esperarse, una especulación sobre su capacidad de conservar o desmantelar interpretaciones antiguas sobre sus propiedades científicas y medicinales." Las distintas interpretaciones colectivas de los objetos sugieren que la colección adquiere significado histórico, porque se trata de un acto deliberado de selección de objetos cuya exposición pública produce funciones comunicativas. Es decir, se trata de objetos que producen sentido porque pertenecen a una gramática objetivada. (Morales, 2006, p. 35)

El catálogo impreso en este caso dista del simple registro de elementos, y se trata más bien, según Findlen, de que hay un proceso de interpretación, en el que se leen los valores modernos mediante los cuales se interactuaba con el mundo objetivo:

(...) los catálogos tienen el propósito de contextualizar los objetos. Construyen una narrativa literaria de la observación de objetos diferenciada de la experiencia de la visita al museo. En este sentido, el catálogo construye otro tipo de lector diferente al visitante o paseante. El catálogo es producto de la difusión de la imprenta, con lo cual se alcanzó a un número de lectores mucho más grande que el de los patricios. De hecho, para boticarios y médicos la publicación de un catálogo era su misión principal. (Morales, 2006, pp. 38-39)

La escritura científica va más allá del catálogo y se entrelaza con la museografía misma, constituyendo una lectura enciclopédica, que ordena el universo. Se construye entonces un mundo de observación dentro del terreno visual de la escritura de la ciencia:

De la segunda mitad del siglo XVI en adelante se plantea, en el laboratorio museístico, esa probabilidad de asociar observación, experimentación, texto y verdad. (...) la observación de la naturaleza conlleva la construcción de un mundo de observación y, por lo tanto, de una determinada producción de sentido. La noción de verdad científica servirá para la comprensión de un mundo históricamente determinado. (Morales, 2006, pp. 40-41)

La escritura - y particularmente a partir de la imprenta, que sustenta el pensamiento en el campo visual — enlaza al museo y a la práctica del coleccionismo en cuanto productos 
de la modernidad. En realidad, el museo y el coleccionismo son productos modernos que se enlazan a partir del pensamiento sustentado en la escritura. Podría decirse entonces que el museo impreso sería la alegoría de dicha intrusión de la modernidad en el espacio del museo.

\section{EL MUSEO COMO IMPRESO}

Es en este contexto que surge el museo impreso. Me refiero aquí a las publicaciones que, entre los siglos XVII y XIX, designaban obras de carácter enciclopédico y misceláneo, con diferentes orientaciones temáticas.

Entre las primeras formas de museo impreso, encontramos el célebre Museo Cartaceo - Museo del papel de principios del siglo XVII. El erudito italiano y mecenas de arte Cassiano dal Pozzo (1588-1657), quien además estaba interesado en la alquimia y era considerado una figura fundamental dentro de la comunidad científica europea, comenzó alrededor de 1615 una colección compuesta por ilustraciones de artistas del Quattrocento y del Alto Renacimiento, además de cientos de dibujos hechos por encargo a artistas contemporáneos menos conocidos, que seguían los patrones propios de la Antigüedad. La colección, compuesta por más de 7.000 acuarelas, dibujos y grabados, se denominó Museo Cartaceo. Con la ayuda de su hermano, Carlo Antonio Cassiano — con quien compartía sus intereses científicos afines al coleccionismo-, dal Pozzo logró dar acopio a una significativa colección que incluía ilustraciones de escultura y arquitectura romana, botánica, geología, ornitología y zoología. ${ }^{8}$

La iniciativa de dal Pozzo no partía de intereses artísticos sino científicos, ya que pretendió tener un documento visual de cada adelanto científico y descubrimiento arqueológico del momento, gracias a la información de primera mano que filósofos y científicos le entregaban, entre los cuales se puede contar a Galileo Galilei, y también porque el afán de compilar libros, cuadros, fragmentos arqueológicos, entre otros, terminaron configurando un centro de investigación y estudio. El Museo constituyó entonces un intento por compilar el conocimiento humano de forma visual, por lo que constituye una fuente de información de primera mano respecto a la historia cultural (incluyendo la intelectual y científica) de la Europa del siglo XVII.

Sin embargo, no es sino hasta el siglo XIX cuando los museos impresos proliferan, aunque esta vez designan publicaciones periódicas no diarias (término acuñado por Juan Miguel Sánchez Vigil), por lo que bien les cabría la designación de "museos hemerográficos", aunque continuaremos con el término de "impresos", por las implicaciones de su surgimiento. Chantal Georgel proporciona la definición más general que podría atribuirse a este tipo de publicaciones:

El museo impreso es una obra enciclopédica o universal, por cuanto trata de los temas más diversos —ciencias, letras o artes, pero también industria, moda, teatro o incluso caza-y está destinado a un público variopinto: señoras, señoritas o caballeros, o simplemente a "todo el mundo". En efecto, el museo impreso prolifera en el siglo XIX; libros, periódicos o álbumes se adjudican, unos tras otros —en ocasiones con carácter efímero- el título de 'museo'. (Musée d'Orsay, 2015)

Georgel trabaja con mayor precisión la existencia de los museos impresos en la Francia decimonónica en su artículo "El museo como metáfora en la Francia del siglo XIX" (Georgel, 1994), donde el museo aparece (desde una perspectiva posrevolucionaria que traduce la posesión de colecciones en la reapropiación colectiva del patrimonio) como una institución con un 
fuerte poder simbólico, y el uso del término por parte de las publicaciones es un ejemplo de esto. En Francia, entre 1806 y 1914, más de setenta publicaciones llevaban la palabra museo en sus títulos, siendo los más populares el Musée comique (1851), Musée Philipon (1843) y Musée parisien (1848), y principalmente el Musée des familles (1833).

En el encuentro del museo con el impreso, y principalmente con la prensa, ve Georgel la metáfora de la institución enciclopédica por excelencia, dedicada a la educación de toda la sociedad, proyecto ilustrado que hereda el siglo XIX. Los museos impresos por lo general constituían tratados de costumbres y comportamientos sociales, pero aun cuando parecían tener intereses puramente artísticos, o de entretención (mediante la ilustración de curiosidades de otros lugares del mundo, por ejemplo), constituían una directriz en cuanto a los cánones de la sociedad, ya que la idea del gusto, de lo "exótico", o incluso, de lo teratológico también moldea el cuerpo social. Aunque en realidad la idea de "educación para toda la sociedad" resulta poco realista en la práctica (desde los criterios actuales de educación y sociedad/comunidad), es una visión de museo que, investida de gran autoridad, tiende a suplantar otras representaciones, proceso que apoya el museo impreso y la periodicidad de su publicación.

Los museos, señalados como lugares de exhibición, de uso y privilegio de la imagen, también van a ser catalogados de la misma forma en su versión impresa, y pretenden justificar su valor gracias a la posibilidad que otorgan al lector de poseer una colección privada de reproducciones (artísticas o científicas), cuya contemplación sería imposible en otras circunstancias, por lo cual investía al individuo de cierto prestigio cultural, de alguna manera similar al del poseedor de un gabinete de curiosidades, y al igual que estos, los museos impresos buscaban constituirse como mundos en microcosmos a partir de un orden específico, la unidad en la multiplicidad.

Así mismo,

La imagen de museo ofrecida en las páginas del "museo impreso" no era tanto la de un sitio de conocimiento o incluso del poder, sino, de forma más simple y evidente, la de un lugar de moralización. El museo era una escuela de moralidad, una respuesta directa a uno de los principales objetivos culturales del siglo, sobre todo la idea del honor que floreció bajo el Segundo Imperio. Entre las obras reproducidas por los "museos" predominaron los retratos de familia y las escenas de género. (Georgel, p. 120) ${ }^{9}$

Entonces, los museos impresos recogen en sí mismos una idea de configuración de la sociedad y, con ella, de construcción de nación, lo que no es ajeno a los museos presentes en Sur y Centroamérica, como se verá más adelante.

Los museos impresos privilegiaban la contemplación de la imagen, y si se tiene en cuenta su vinculación con la prensa, es necesario considerar el momento y las técnicas necesarias para que fuera posible la inclusión de la imagen en este tipo de publicaciones:

La imagen como ilustración de los textos fue aplicada a la prensa periódica en los primeros años del siglo XIX. El periódico londinense The Times reprodujo en sus páginas los apuntes tomados durante el sepelio del almirante Nelson en 1806, y más tarde las principales publicaciones románticas incluyeron grabados de carácter documental e informativo, entre ellas el semanario parisino L'Illustration (1843) y los londinenses The Weekly Chronicle (1836), Punch (1841) y The Ilustrated London News (1843). Desde la aparición de los periódicos ilustrados en 
el primer tercio del siglo XIX hasta la aplicación de la técnica del fotograbado en sus últimos años, la mayoría de las revistas centraron sus contenidos en la cultura, la política y las costumbres. (Sánchez, 2008, p. 32)

En general, se considera que durante el siglo XIX las revistas ilustradas son el espejo del mundo, por su carácter informativo y visual, lo cual se agrega al fuerte papel cultural que ostentan, como señalaba Georgel.

Las imágenes - fueran grabados, dibujos o fotografías- podían tener una función complementaria, independiente o como conjunto informativo y documental. Sánchez Vigil muestra que, además de las denominaciones comunes de 'revista', 'gaceta', 'boletín', 'periódico', 'semanario', 'archivo', y 'magazine',

(...) otros términos empleados para designar los contenidos fueron panorama, museo y mundo, utilizados en sus respectivos significados de vista general, compendio de obras que se exhiben y se muestran, o exposición de hechos o sucesos ocurridos en todas partes para destacar su carácter informativo universal en una evidente intención de globalizar. (Sánchez, 2008, p. 38)

Idea que, aunque dota de cierta particularidad el empleo del término, no lo reviste del carácter ideológico que le atribuye Georgel.

Así como hiciera Georgel con Francia, Sánchez Vigil señala los principales museos impresos de la España del XIX: En España: El Museo de las Familias (1843-1871), emulando al francés, "fue dirigido por José Muñoz Maldonado y llevó el subtítulo "Lecturas agradables e instructivas"; sus contenidos eran especializados y tratados con una intención pedagógica" (Sánchez, 2008, p. 39); El Museo Universal (1857-1869), ${ }^{10}$ y El Museo Literario (1863), “Periódico Ilustrado, Literario, Científico e Industrial" que se publicaba en Valencia con doble pliego marquilla y una lámina firmada por un autor distinto cada semana.

Por su parte en México, durante el siglo XIX hay un periodo clave para la prensa, en el cual, de 1830 a 1857, se procuraba la promulgación de un orden nacional, en medio de la inestabilidad política y social del momento, que generó un revisionismo ideológico que afectó profundamente la sociedad. Las publicaciones periódicas, según Érica Segre, eran fundamentales para contrarrestar la débil imagen del México postcolonial, entre los mismos mexicanos pero también ante los extranjeros:

La prensa cultural, en particular, evitó las polémicas abiertas de periódicos enemistados, en un intento de fomentar la homogeneidad cívica e intelectual. Los editores profesaban su pertenencia a un modelo integrador y consensuado de transmisión cultural, que pretendía inculcar valores similares en sus lectores. (Segre, 2007, p. 5) $)^{11}$

Segre argumenta que la prensa tendría en aquel momento la función de proporcionar un canon formativo, cuando la oferta tradicional educativa y cultural había sido suspendida. Los periódicos eran retóricamente útiles, pero ineficaces para logar por sí mismos la restauración de los valores nacionales. La difusión cultural se concentraba en las tertulias que emprendieron empresas culturales colectivas, para lo cual hicieron uso de medios como la prensa. En este contexto surge El Museo Mexicano. O miscelánea pintoresca de amenidades curiosas e instructivas, de Ignacio Cumplido (1843) donde, para Segre, la idea del museo impreso está subsumida en la del "gabinete de curiosidades", pues la galería instructiva estaba compuesta por cuadros de costumbres, en los que se identifican "los paralelos implícitos con una expo- 
sición de un museo nacional, el diorama portátil, el gabinete de curiosidades" (Segre, 2007, p. 24), ${ }^{12}$ y que contribuyeron a la representación de la nación en microcosmos y su apropiación por parte del lector.

\section{LA IMPRENTA DE TIPOS (HUMANOS) MÓVILES: EL MUSEO DE CUADROS DE COSTUMBRES Y VARIEDADES}

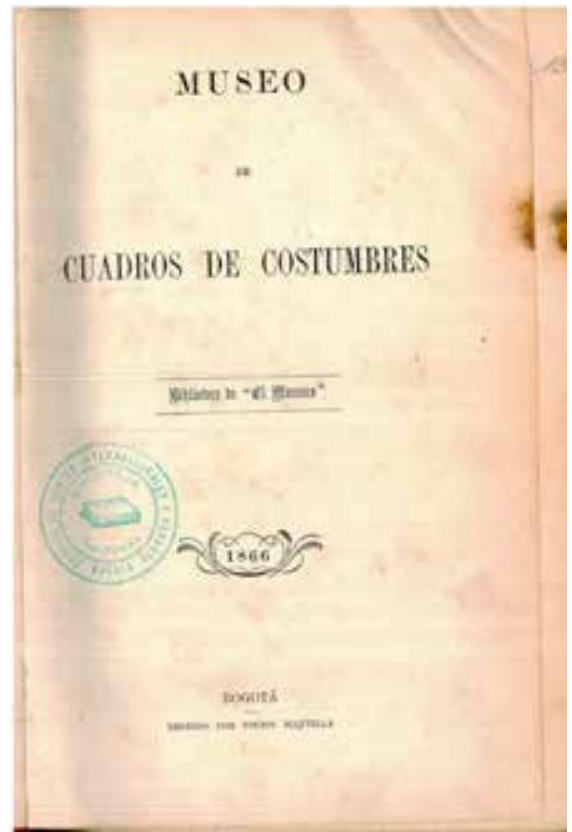

Figura 1. Carátula de la edición del Museo de Cuadros de Costumbres, volumen 1, impreso por Foción Mantilla en 1866, y conservado en la Biblioteca Nacional de Colombia con el número de ubicación G 11022. (Colección general de la Biblioteca Nacional de Colombia).

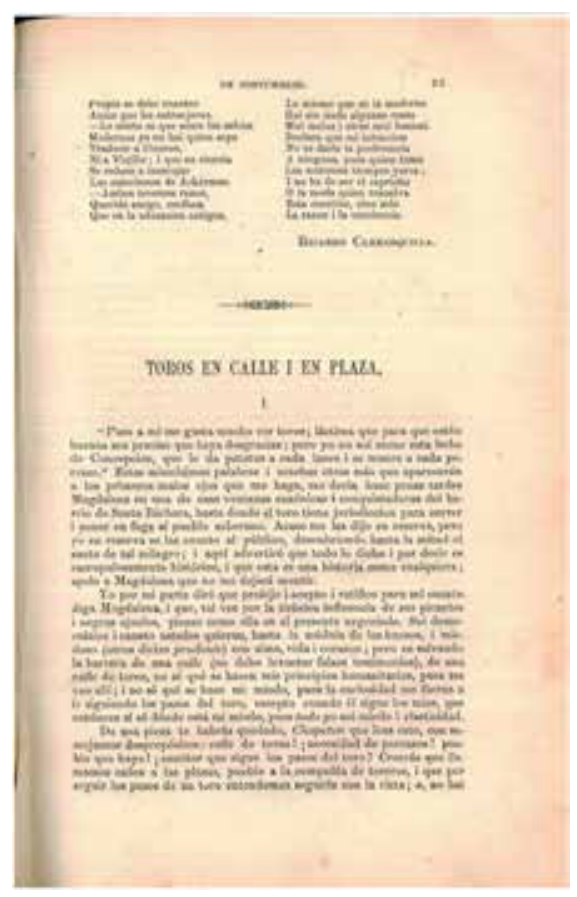

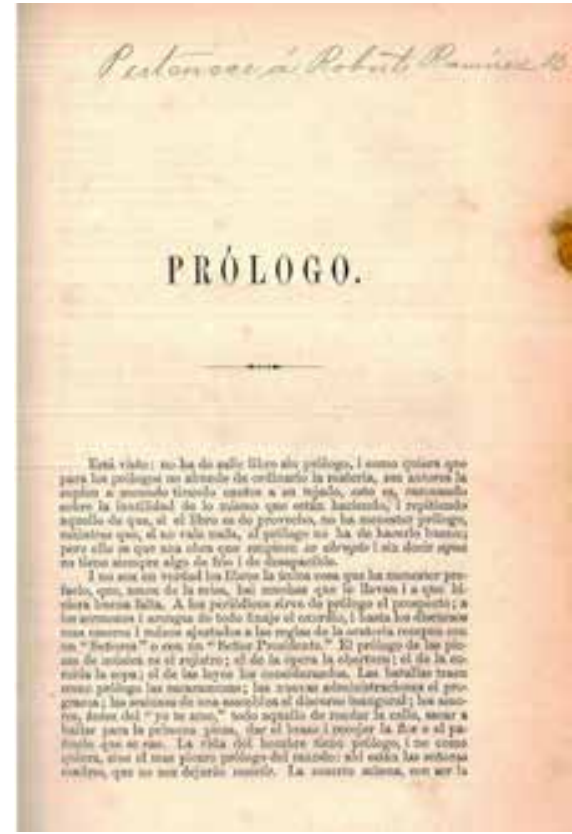

Figura 2. Primera página del prólogo de la edición conservada en la Biblioteca Nacional, con la nota "Pertenece á Roberto Ramírez B.," escrita a lápiz. Ramírez B. fue un reconocido editor $y$ telegrafista, que a finales del siglo XIX y principios del XX publicó en Bogotá varios textos, como $E I$ telegrafista colombiano: texto de telegrafía teórico-práctico, Historia del Telégrafo y El morse: texto de telegrafía teórico práctico. (Colección general de la Biblioteca Nacional de Colombia). 
Según Beatriz González Stephan,

(...) no es sino hasta el siglo XIX con el surgimiento de la burguesía que la actividad coleccionista adquirió no sólo una difusión masiva, sino la impronta de una política estatal. Es entonces cuando el coleccionismo, articulado a un saber - porque las colecciones son clasificadas, ordenadas, jerarquizadas-, fue puesto al servicio de una voluntad de poder, de dominación euro-occidental o de dominación hegemónica nacionales. (González, 2000, p. 7).

Como evidencia, un museo impreso de la Colombia decimonónica.

Durante la segunda mitad de siglo se publicó en el país el Museo de cuadros de costumbres y variedades, cuyo primer volumen de seis fue editado en 1866 por la tertulia El Mosaico y su figura principal, José María Vergara y Vergara, quien se encargó de realizar un volumen con la selección de cuadros de costumbres previamente publicados en la revista El Mosaico, principal espacio literario de la tertulia.

Los cuadros de costumbres -en cuanto subgénero del costumbrismo caracterizado por la descripción ensalzadora, satírica o añorante de tipos humanos, generalmente populares, y sus comportamientos, hábitos, tradiciones, valores y principales oficios, circunscritos a una región en particular - constituyen una puerta para entrar en las representaciones de pueblo y de nación de la época y en el imaginario de los mismos escritores, en quienes recaía —por constituir también figuras en ámbitos políticos, científicos, estéticos, entre otros- el impulso cultural de la sociedad, proyecto que, como se dijo anteriormente, es un remanente de la llustración.

Por otra parte, aunque resulte adecuado afirmar que

(...) el lenguaje costumbrista se esfuerza por aproximarse no a la realidad bruta sino a las formas de composición de los grabados de la época. Los cuadros de costumbres se pintaban literalmente. (Colmenares, 1988, p. 265)

Cuando Eugenio Díaz, cofundador de la tertulia El Mosaico, toma como epígrafe para su afamada novela Manuela la sentencia a la escritora española Fernán Caballero "los cuadros de costumbres no se inventan, se copian", señala con ello una conciencia del uso del lenguaje respecto a una realidad que se plantea como total: se pretende sustentar la validez del cuadro de costumbres en cuanto calco de la realidad, lo cual expresa el carácter científico del museo del siglo XIX, que

(...) otorgó prioridad a la investigación científica basada en la autenticidad y objetividad de las colecciones; en este sentido, las exhibiciones servían para mostrar y difundir las evidencias del conocimiento científico, práctica con la que se plasmó la noción de pieza única y, por lo tanto, la de colección de originales. Esta concepción de las exhibiciones hizo del museo una enciclopedia ilustrada de las cosas del mundo. (Morales, 1999, p. 245)

A la pretensión de originalidad subyace, no obstante, la urgencia del nacionalismo emergente.

En El Mosaico, periódico de la tertulia con el mismo nombre, y primer espacio que recoge los cuadros de costumbres antes de su selección para el Museo, el nacionalismo se articula y da sentido a sus múltiples manifestaciones. En torno a la publicación de la revista y el proyecto posterior, el Museo, los miembros de la tertulia expresaron la voluntad de consagrarse a fabricar una cultura nacional, en parte como respuesta al afrancesamiento y a la influencia inglesa, 
según se verá posteriormente. Aquí, el Museo entra en las consideraciones generales que resultan pertinentes para los museos de finales de siglo, en particular los de ciencias naturales:

La vocación didáctica por la expansión del mensaje científico a un público cada vez más amplio determinó, en última instancia, el desarrollo del discurso museográfico como la mediación necesaria para que los coleccionismos científico y patriótico resultasen herramientas eficaces de enseñanza. En la era de la industrialización europea y norteamericana, los objetos exóticos sufrirían una reinterpretación que obligará a una relectura de la historia en un sentido procesal y absoluto. (Morales, 1999, p. 250)

Como parte de una ideología que se pretende instaurar a partir de la implementación de modelos adecuados para tal fin, se establece una manera apropiada de representación, y se elige un género (costumbrismo) que desarrolle directamente los lineamientos propuestos.

Sin embargo, está presente el problema de la emergencia en Hispanoamérica de un modelo nacional, que toma como precedente un paradigma europeo de homogeneidad, unidad e indivisibilidad, y que se pretende establecer dentro de un marco histórico preciso, caracterizado por las discontinuidades políticas, el ascenso de los partidos Liberal y Conservador al poder, los periodos de crisis y de conciliación. De allí la afirmación general de que la Nación emergió de manera abrupta en América Latina. Tras la disolución de la monarquía española, el desafío para la república en nacimiento fue la configuración de un Estado y posteriormente la construcción de una Nación.

Dentro de esta elaboración de imaginarios nacionales, el cuadro de costumbres es un género que se presta para tales intenciones; por sus características acompañaba bien a la prensa y se inscribía dentro de la tradición de la pintura costumbrista y de las producciones escritas de los viajes ingleses a finales del siglo XVIII, aunque su llegada y popularidad en América Latina vino por cuenta de la influencia española en el continente.

Según su definición, los cuadros de costumbres eran representaciones de la vida social, inspiradas o "copiadas" del natural. Sin embargo, además de cumplir una función de representar al pueblo, se les solía atribuir otra función de tipo moral: la misma narración de los hechos debía dejar al descubierto vicios y virtudes y apuntar a la corrección de hábitos perjudiciales y anticuados. (Gordillo, 2003, p. 48)

El Mosaico, de donde provino el contenido para el Museo, se impuso la consigna de no hablar de política ${ }^{13}$ y restringirse al campo literario:

Pero cuán nublado se presenta aún el horizonte en rededor! Cuán triste y desolado el campo cubierto con los despojos de la feral guerra civil, en cuyo prólogo nos hallamos todavía!... Cuán... pero es forzoso guardar silencio sobre este punto, porque “El Mosaico," a pesar de ser Mosaico, le es prohibido, absolutamente prohibido, entrar en apreciaciones políticas, ni en cuestiones de partidos, sin duda por no ennegrecer sus cuadros apacibles y gayos colores con sombras oscuras y melancólicas. (Caicedo, 1860, p. 257)

En periódicos que se consideraban como exclusivamente literarios se hizo presente una elaboración a partir de la tradición, ya que toda selección implicaba una forma de autoridad que se expresaba en una noción de literatura, lo que de alguna manera se consideraba como el canon que debía establecerse y su relación con el que ya había sido aprobado. Este tipo de literatura pretende entonces construir una imagen del pueblo portador de la soberanía nacional, 
con la crítica de las costumbres populares y de la "moral pública". Son tres entonces los criterios que vertebran el canon por establecer: educación, moralidad, nación.

Por lo anterior, es posible señalar en el Museo de cuadros de costumbres y variedades un sentido que dirige la colección y exposición de los cuadros con un objetivo general de construcción de nación y promoción del progreso, dentro de una visión políticamente conservadora, que tiene como trasfondo, en lo político, las guerras bipartidistas, y en lo social y cultural la pérdida de espacios para la promoción e impulso del conocimiento por parte de la aristocracia ante el surgimiento de la burguesía y sus nuevas herramientas de expresión, entre las que se cuentan la prensa política.

Es importante notar también que este museo impreso cuenta con el precedente de la Comisión Corográfica, y en general de la situación de las demás instituciones que procuran instaurarse dentro del orden nacional por sus propuestas científicas, artísticas y educativas, como es el caso de la tertulia El Mosaico y la serie de proyectos en su haber. Este trasfondo institucional del proyecto le da sentido y consistencia al afán compilatorio que expresó Vergara en el Museo; además, también hubo un esfuerzo por conservar el contenido expuesto en la publicación original:

Anualmente la publicación [El Mosaico] se acompañó de una pasta, un índice y una dedicatoria con el fin de elaborar un tomo. (...) La prensa literaria procuró entonces perdurar no sólo para la historia sino como posibilidad de entretenimiento para hombres futuros, al inducirlos a conservar el periódico. (Acosta, 1997, p. 83)

El Museo de cuadros de costumbres y variedades constituyó otro volumen de este tipo, en el que los cuadros más representativos resultaban dignos de ser publicados nuevamente y conservados a posteridad. Esto — junto al impulso de Vergara y sus contertulios por legitimar la literatura nacional de cara a su pasado colonial, pero con el fin de impulsar su desarrollo a futuro, como se verá posteriormente - configura lo que se podría considerar una "polifacética" búsqueda del patrimonio nacional, pero que en sí es la determinación de lo que debe ser considerado como tal, en función de un pasado que se escenifica conforme a las necesidades del presente.

Entre 1858 y 1872, cuando Colombia atravesaba por una grave crisis política, social y económica, se conforma la tertulia de El Mosaico, dedicada específicamente a asuntos literarios. Los fundadores de este espacio fueron José María Vergara y Vergara, periodista y político conservador, y Eugenio Díaz, autor de cuadros de costumbres y de la primera gran novela costumbrista, Manuela (1859). La tertulia es entonces consecuencia de la asociación de la elite intelectual, la cual —-mediante la configuración de espacios como la revista El Mosaico, la biblioteca con el mismo nombre y el Museo de cuadros de costumbres y variedades, entre otros- procura neutralizar el panorama general de crisis y atraso en el país mediante el ejercicio escrito.

Andrés Gordillo señala que El Mosaico aparece con el fin de contrarrestar la falta de instituciones que se dedicaran al fomento de las artes y de la literatura en el país, lo que se traducía en una sensación de decaída por parte de la elite cultural de la vida social:

Las comunidades científicas y académicas que se habían concebido con tanto entusiasmo y ambición después de la Independencia no alcanzaron a tener mayor continuidad. De ellas, entre las que se cuentan los proyectos de 1826 y 1832 de crear una Academia Nacional seme- 
jante al Instituto Real de Francia, sólo permanecía en pie para 1858 un Museo Nacional empo-

brecido y saqueado, que tenía dificultades para funcionar normalmente. (Gordillo, 2003, p. 25)

Debido a las continuas crisis políticas era problemático establecer y dar continuidad a una institución de este tipo, dirigida por la élite literaria, científica y artística del centro del país. Así mismo, el Mosaico se vio afectado por la discontinuidad partidista en el gobierno de Colombia: desde su creación en 1858 siguió un ritmo continuo hasta 1860, cuando se suspende por primera vez hasta 1864 durante el gobierno de Tomás Cipriano de Mosquera; en 1868 cierra nuevamente por el segundo gobierno de Mosquera hasta 1871, y finaliza de manera definitiva hacia 1872.

Entre las instituciones científicas con las que la tertulia guarda relación, más allá de la cercanía temporal, se encuentra, como se mencionó con anterioridad, la Comisión Corográfica (1850-1859), contratada precisamente por Mosquera y comandada por el geógrafo italiano Agustín Codazzi, que procuró la exploración de la botánica, la geografía y los grupos humanos presentes en el territorio ofreciendo una visión sistemática y detallada del país, ganando así un importante espacio dentro de la ciencia del siglo XIX. El objetivo fundamental de la Comisión era netamente cartográfico y procuraba generar la información geográfica adecuada para que el gobierno estableciera políticas racionales respecto al manejo del territorio; así mismo, buscaba realzar el potencial del país para la exportación de productos, en particular agrícolas, dentro del modelo económico mundial característico del siglo XIX, mediante el inventario de sus recursos. Finalmente,

(...) la Comisión debía hacerse cargo de realizar observaciones sobre las gentes y sus costumbres en las distintas zonas visitadas, de manera que fuera posible determinar las diferencias de región a región, y de esta forma contribuir a la formación de una identidad nacional, donde se enfatizaban los elementos comunes entre distintas zonas, pero a su vez las diferencias regionales. (Guhl Corpas, 2005, p. 29)

La Comisión se disolvió poco después de la muerte de Codazzi en 1858; debido a ello, y al olvido de sus trabajos por razones políticas a finales del siglo XIX, como señala Guhl Corpas, el primer objetivo fue el único que se llevó a cabo, los demás solo parcialmente. En el espacio de la cultura nacional, fue El Mosaico quien se encargó de procesar parte del legado. Esta tertulia procuró difundir el trabajo de la Comisión y al mismo tiempo definió elementos de su trabajo a partir de lo obtenido por ella. Ha sido ampliamente citada la afirmación que el mismo Vergara hiciera en el primer volumen de El Mosaico:

(...) nuestra patria es totalmente desconocida en su parte material y moral no sólo de los extranjeros que a causa de la ignorancia nos desprecian como a una turba de bárbaros; sino lo que es más triste, es desconocida de sus mismos moradores. Así, pues, en ninguna parte más que en pueblos nacientes como el nuestro, la prensa está llamada a ejercer una alta influencia y a producir ingentes resultados (...) A los que estamos separados de esa lucha enconosa de las pasiones públicas nos toca trabajar con ahínco por hacer conocer el suelo donde recibimos la vida, y donde seguirán viviendo nuestros hijos. A nosotros nos toca el elogio de las grandes acciones, la pintura de nuestros usos y costumbres. (Vergara y Vergara, 1858).

De allí el estilo costumbrista de una gran cantidad de escritos que hicieron parte del cuerpo de la revista, ya que este constituyó una estrategia adecuada para la creación de un mapa cultural del país como mosaico, lo cual creaba una noción de "unidad en la diversidad". En la 
revista El Mosaico, tras la sección inicial presentada como artículo editorial, seguía la literaria, conformada por cuadros de costumbres, novelas por entregas, dos o tres poemas, y algún artículo relacionado con literatura. Existía además una sección científica dedicada a investigadores en tierra americana, anuncios meteorológicos, y finalmente, una sección dedicada a la correspondencia con los suscriptores, a la cual se procuró dar un espacio significativo dentro de la publicación. Vergara y sus contertulios buscaron ampliar el grupo editor generando un público cooperador, restringido pero "representativo" del más amplio, que no solo opinara de los textos, sino que podía aportar sugerencias concretas de corrección: escritores que querían participar del periódico y se reunían en torno a la imprenta, o mediante correspondencia. Se configuraba así un grupo sólido de lectores-escritores-lectores que participaban en la conformación de diversas propuestas de escritura, pero que de todos modos se movían dentro del canon impuesto por la misma elite: no solo estaba la censura en torno a consideraciones de orden político y moral que caía en general sobre los escritores de la nación, sino que esa noción de literatura dentro de la cual se promovía la colaboración del público estaba cuidadosamente seleccionada, como se verá posteriormente, para responder al discurso federalista en torno al manejo de la naciente República.

El proyecto de la tertulia se establece entonces ante la necesidad de construcción de una idea de nación, de sus características geográficas y el carácter de sus gentes, proyecto que se potencializa en el Museo de cuadros de costumbres y variedades, cuya colección provino de una cuidadosa selección entre los números anteriores de la revista, como afirma Vergara en el prólogo:

(...) guiándonos por nuestros propios recuerdos y por los de varias personas de buen gusto, hemos escogido aquellas piezas que, leídas cuando estaban recién publicadas, habían dejado en el ánimo una impresión agradable; excluyendo aquellas que en los periódicos que hemos hojeado se han ofrecido a nuestra vista, siempre que nos han parecido de escaso mérito. (Vergara y Vergara, Prólogo)

Respecto a la Comisión, valdría la pena señalar que entre esta amplia compilación de cuadros figuran varias crónicas de viaje de algunos de sus miembros.

Los cuadros de costumbres se caracterizan por su estatismo, la acción se retarda y lo que cuenta es la descripción, que en el caso puntual de la publicación permitió establecer los elementos comunes entre poblaciones dispersas en una geografía vasta, azarosa e incomunicadas por falta de caminos, dándoles consistencia dentro de lo que en últimas resulta ser una "comunidad imaginada". Los autores de estos cuadros aprovecharon ese estatismo propio del género para ubicar a los personajes en un espacio determinado, pero suspendidos en el tiempo, e incluso algunos de ellos no requirieron ni siquiera la presencia de personajes u objetos animados (como ocurre en el cuadro titulado El reloj y la pila de Tunja donde se utiliza la prosopopeya para criticar el manejo político de Boyacá), pues con la descripción del lugar, ya fuera un pueblo, una villa o un lugar específico de la ciudad era suficiente.

Difiero en este punto de la opinión de Erna von der Walde, quien reduce la experiencia del lector de cuadros de costumbres a "un deseo (...) de adquirir conocimiento sobre las bases materiales del país más que una curiosidad novelesca"14 (2007, p. 249). Si bien podría considerarse que la mayoría de estos cuadros carece de una trama (con algunas excepciones, como ocurre en el caso del Museo con cuadros como Entre usted, que se moja, o Mis recuerdos de Tibacuy, donde la historia lineal vertebra la descripción), y es la descripción misma 
lo que permite tomar los cuadros como imágenes, fragmentos de realidad, es claro que el componente narrativo constituye algo más que el marco para la descripción, pues dinamiza la composición, permitiendo captar el interés de sus lectores, ${ }^{15}$ razón por la cual las distintas descripciones no se agotan en la enumeración o referencia a los tipos humanos y morales de los cuadros de costumbres (en el caso del Museo: El Correísta: "Ahora, lector mío!, reflexionad si sois mi superior en edad, dignidad y gobierno; reflexiona si eres algún ente de menor cuantía; decidme o dime ¿qué os parece el Correísta? ¿Comprendéis ahora por qué representa gran papel el Correísta?"), estos se representan, se escenifican y se ponen en contexto, se podría decir que hay una ambientación, una necesidad por escenificar el tipo humano o la costumbre a señalar, dotándola de sentido.

Porque en realidad, la construcción de los cuadros se atenía a unas cuantas estructuras básicas, por lo general de oposición: ciudad-campo (en el caso del Museo: Algo sobre tierra caliente, donde se pondera el altiplano gracias a la visión bogotana del paisaje), autóctonoextranjero (Los Diablitos, en la que hay una justificación racional de la fiesta antioqueña, con referentes a celebraciones europeas), tradición-nuevas costumbres (Lo que va de ayer a hoy, respecto a la educación, La nochebuena, con una exaltación religiosa de la costumbre), etcétera, que se repetían constantemente, en un esfuerzo de dar respuesta al discurso federalista que no solo subdividía a la nación en Estados Soberanos, sino que propiciaba su apertura hacia el norte de Europa según la idea liberal de progreso, lo cual era leído desde el espacio conservador (al que pertenecía Vergara) como perjuicio a la tradición y la identidad nacional, con el consecuente declive moral.

Por ello las imágenes en los cuadros no buscan constituirse en pasatiempo o distracción familiar sino, a partir de este, comunicar un modelo, y propiciar su adopción y preservación. En la reproducción de estas estructuras básicas, es entonces su escenificación y ambientación lo que dota de sentido a cada cuadro en particular, y a su vez lo incorpora en el orden mayor de la colección, haciéndose amena, gracias a las estrategias narrativas, y a la vez instructiva su lectura, o de otra forma no habría contado este género con tan amplia popularidad desde los años cuarenta del siglo XIX hasta entrado el siglo XX.

De allí, la posibilidad de revestir la lectura de los cuadros con la idea de un entretenimiento apto, desde el cual se conducían los hilos de esa nación en proceso de construcción:

Sin mayores dificultades, puede distinguirse en El Mosaico uno de los primeros esfuerzos continuados por crear un vínculo emocional del público lector hacia la nación colombiana, tratando de superar la fragmentación regional, la famosa retórica nacionalista del orgullo republicano que era propia de los discursos políticos, así como el pesimismo sobre el futuro del país. Este esfuerzo, que puede ser señalado como una continuación de la Comisión Corográfica por cuanto con él se adelantó la misma tarea de llevar al público una imagen del país en su parte moral y material, se extiende sin embargo en un plazo más largo. (Gordillo, 2003, p. 33)

Por otra parte, aludíamos antes a la adecuación de un lector pertinente para el texto. ¿Pero cuál es ese lector? Debido a que los volúmenes del Museo de cuadros de costumbres y variedades, que llegaron a ser seis (producidos los dos primeros en la imprenta de El Mosaico) fueron distribuidos entre los suscriptores de la revista El Mosaico, respecto al público lector y visitante del Museo el prólogo es claro en la dirección de sus intereses: continúa siendo el mismo lector de los periódicos impulsados por la tertulia, un público y una red de colaboradores que se constituyó con unos criterios patrióticos y elitistas. ${ }^{16}$ 
No obstante, mientras la circulación se restringía prácticamente al interior del país —como muestran las cifras de la revista El Mosaico, con una escasa circulación en el Caribe, Magdalena, Bolívar, y países vecinos como Venezuela— el objetivo del Museo es ir aún más lejos:

Como, según lo hemos dejado ya vislumbrar, abrigamos la esperanza de que nuestro libro sea leído por españoles europeos, queremos dirigir a éstos dos palabras en descargo de nuestra conciencia. (Vergara y Vergara, Prólogo)

Esta afirmación resulta de gran importancia porque determina los criterios de selección que estructuran la colección del Museo, así como el recorrido que se llevará a cabo dentro de este e incluso, el mismo título del museo impreso.

Andrés Gordillo sugiere en su artículo que la preocupación nacionalista se debía en gran medida a su cosmopolitismo. Cuando Vergara y Vergara comenta que

(...) hubiéramos trocado aquel nombre por el de "Los colombianos pintados por sí mismos",

y habría quedado remediada la inexactitud; ${ }^{17}$ pero es el caso que este libro puede ir a Europa (¿quién tiene en nuestros días suerte tan mezquina que no pueda hacer su viajecito al otro lado del charco?), y como los señores europeos están tan atrasados en cuanto a nuestra historia y nuestra geografía, que hasta ahora empiezan a hacerse cargo de que en estas Indias Occidentales hay algo más que indias e indios y de que en ellas ha existido la Colombia primitiva, si llegasen a ver dicho título, nadie podría quitarles de la cabeza que la obra contenía descripción de las costumbres de los venezolanos y de los ecuatorianos juntamente con las de los que éramos neo y ahora somos ex granadinos. (Vergara y Vergara, Prólogo)

Ello permite ver más que un afán de claridad en la información suministrada en la obra.

La preocupación de Vergara hacia el público español tiene que ver con un aspecto fuertemente arraigado en el seno de esta asociación de intelectuales: la idea liberal de impulsar el progreso de la nación mediante la promoción de la inmigración, atrayendo europeos del norte y norteamericanos por su espíritu de empresa; sin embargo, Vergara y la mayoría de sus contertulios eran conservadores, y para ellos el contacto con franceses e ingleses, manejado inadecuadamente, llevaba a la pérdida de las tradiciones en perjuicio de la patria, por ello el impulso de Vergara tendía a reafirmar los lazos con lo que consideraba el germen, el origen de la nación: la madre patria, España.

Pese a su carácter opuesto, las visiones de conservadores y liberales se movían dentro de un mismo interés por ese progreso a partir de la inmigración, de allí la necesidad de mostrar no tanto la "cara positiva" del país, sino más bien su carácter pintoresco, representado en sus paisajes, en sus gentes, en sus fiestas, y demás. Y precisamente, uno de los objetivos principales de la Comisión Corográfica era el de atraer inmigración extranjera, ya que como señala Von der Walde, las cuatro estrategias principales que el gobierno consideraba necesarias para impulsar el progreso eran: educación, industria, caminos e inmigración. En 1849, el secretario de gobierno del entonces presidente Tomás Cipriano de Mosquera afirmaba que

En la Nueva Granada se notan todas las condiciones de los países que necesitan más el poderoso fomento de la inmigración: extenso territorio, población poco numerosa, eterojeneidad de razas, languidez industrial, escasa i difícil comunicación. Necesitamos, por tanto, civilizar i poblar nuestros baldíos, aumentar la raza blanca, dar aliento al trabajo i las artes, desarrollar los fecundos jérmenes de riqueza que encierra nuestro vasto suelo, impulsar las mejoras materiales i nuestros progresos morales. (citado en Von der Walde, 2007, p. 249). 
Debido a que nunca se formalizó un programa puntual para estimular la inmigración impulsado por el gobierno,

(...) quedó como único recurso el de usar un "medio indirecto" a través de la prensa, en la que se podía publicar descripciones del país, de "las ventajas naturales, políticas i sociales", para atraer a los extranjeros (...). Se consideraba que las láminas creadas por los pintores de la Comisión podían servir para tal fin, es más, que esta era su principal razón de ser, pero nunca se publicaron, quizás por falta de dinero. (Von der Walde, 2007, p. 249).

Entonces, los textos presentes en el Museo de cuadros de costumbres y variedades funcionaron precisamente a la manera de imágenes, de cuadros representativos de los paisajes o personajes característicos dentro de esa idea de nación que no solo se debía construir en el seno del país, sino también instaurar ante los extranjeros. El prólogo del Museo sugiere esta posibilidad de ver los cuadros como imágenes: además de la mención al primer nombre tentativo de la publicación, "Los granadinos pintados por sí mismos", afirma Vergara y Vergara que

(...) si las figuras humanas que se ven en el vasto cuadro que forma nuestro libro han de servir para dar a los que no nos conocen alguna idea de lo que somos y de lo que hemos sido, sería lástima que la pintura careciera de campo y de cielo, y ni cielo ni campo se echarán menos en ella, merced a las descripciones de lugares que se han introducido. (Vergara y Vergara, Prólogo)

Al respecto, resulta llamativo un texto de José Manuel Marroquín, publicado en 1886 que se reproduce a continuación de forma parcial, y que habla por sí mismo en cuanto al fundamento del Museo desde lo que se viene señalando:

Un amigo mío que proyecta un viaje al estranjero, me preguntaba en estos días qué objetos podría llevar para dar en los paises que iba a recorrer alguna idea del estado de nuestra civilización, de nuestras costumbres y principalmente de lo que puede llamarse nuestra fisionomía moral.

En primer lugar (le dije yo), en primer lugar, no lleve usted muestras de nuestro tabaco, de nuestra quina, de nuestras esmeraldas ni de nuestra vainilla; sobre todo, no lleve usted mariposas de Muzo: todas estas cosas acaban de confirmar a los europeos en la opinión que tienen de que nuestra salvaje i vigorosa naturaleza es lo ménos salvaje que hai en nuestra vírjen América, i lo único que en ella merece atención y estudio.

En segundo lugar, debe usted llevarse unos cuantos ejemplares de los "Cuadros de costumbres" que acaba de publicar el señor Foción Mantilla. ${ }^{18}$ Nada puede dar a los estranjeros una idea más perfecta de lo que usted llama nuestra fisionomía moral, sin dejarla de dar al mismo tiempo de lo material de nuestro país, que aquella obra. Nuestra historia da a conocer los acontecimientos políticos de que ha sido teatro nuestro suelo, nuestra jeografía es, como todas las jeografías, un catálogo de nombres, de distancias, de grados sobre el nivel del mar, de latitudes i lonjitudes. Nada, nada se ha escrito hasta ahora que pueda hacernos conocer de los estraños bajo el aspecto moral i social, como el libro que estoy recomendándole a usted. (Marroquín, 1886, p. 3)

Se puede decir entonces que los cuestionamientos en torno a la necesidad de la inmigración afectaron las formas de cómo establecer el "carácter" de la nación y de sus gentes. 
A la idea del progreso impulsado por la inmigración se sumaba, además, el mercado en ascenso, como muestra de los avances industriales y la conformación de la burguesía:

La segunda mitad del siglo XIX desplegó la gramática de una nueva economía de la representación como una de las claves de la también nueva política de las formas, resultado del capitalismo industrial (...) La nueva política de la representación — del performance espectacular - habría de ser hábilmente aprovechado tanto con fines estatales como económicos. (González, 2000, p. 4)

A la par que se instauran las exposiciones universales como precedente a la vez del museo, la galería y el centro comercial, la misma estrategia coleccionista que se adaptaba a un mercado en crecimiento, a partir de la maquinaria escritural,

(...) sirvió para acumular artefactos simbólicos —antologías, parnasos, museos, academias, diccionarios, enciclopedias, historias...- que podían decir de una cultura nacional. (González, 2000, p. 6).

La pretensión moralizante que subyace en los cuadros de costumbres tenía la doble función de mostrar un sustrato cultural elaborado para la nación en crecimiento, tanto en la exhibición del carácter de sus gentes como en la creación literaria propiamente dicha.

Sin embargo, vuelve a ser pertinente preguntarse por qué el público extranjero al que Vergara invita al Museo es español y no europeo en general. En primer lugar, a pesar del distanciamiento de las arengas políticas que los miembros del Mosaico pretendieron establecer, resulta inevitable que este tipo de filiaciones afecte directamente las decisiones y los posicionamientos que determinan los proyectos de la tertulia; entonces, al momento de definir la colección para el Museo, imperó en gran medida la ideología conservadora de José María Vergara y Vergara, dentro de la cual se instaura una fuerte crítica al "afrancesamiento" del colombiano, que degeneraba en una pérdida de las costumbres autóctonas que atentaba contra la identidad nacional:

Nada más opuesto a la propuesta de Vergara y de los mosaicos, que la cultura eurocéntrica de las élites colombianas del siglo XIX. En efecto, cabe precisar que las élites culturales no han empezado a desarrollar una red de referencias que conduzcan hacia una tradición cultural propia, porque en buena medida, la alta cultura es, propiamente hablando, la cultura europea. (Gordillo, 2003, p. 33)

Los cuadros de costumbres constituían entonces no solo la oportunidad de desplegar ante el extranjero un abanico de imágenes cuidadosamente seleccionadas con el fin de que se diera una idea "correcta" de la república, sino que permitía desarrollar el impulso de conservar las tradiciones consideradas como propiamente colombianas mediante su señalamiento y exaltación, a la vez que se reprimían las actuaciones que atentaban contra la moral.

Como respuesta al "afrancesamiento", y siguiendo su preocupación por gestionar una identidad de nación específica y propiamente colombiana, pero que se ve legitimada por su relación con la tradición hispana —en donde están asentadas sus raíces—, José María Vergara y Vergara publicó su obra Historia de la literatura en la Nueva Granada (1867), donde pretende validar la literatura colonial colombiana, y con ello la del momento, mediante la evidencia de sus nexos con la rica producción hispánica. Así, las obras colombianas tienen valor en sí mismas, y a la vez están respaldadas por una tradición a la que dotan de continuidad. 
Si hoy somos algo, no nos improvisamos; ese algo de hoy depende de algo de ayer, y ese ayer es nuestra historia antigua, es buscar nuestro propio origen, es estudiar no solo a España, sino a nosotros mismos. (Vergara y Vergara, 1867, p.114)

La historia de la literatura de Vergara se construye como respuesta a la consideración política de la nulidad del pasado colonial en tierra colombiana: la presencia de los españoles, según esto, solo trajo consigo el atraso político, social y cultural al territorio, e hizo aún más complejo el establecimiento de una república competente. Vergara y sus contertulios utilizaron entonces el espacio de la Historia de la literatura en la Nueva Granada y del Museo para construir una nacionalidad aferrada a sus tradiciones, y enriquecida por ellas.

\footnotetext{
Vergara partió de una mirada hacia el pasado y hacia el futuro. Solo construyendo dicho pasado podía pensarse en una literatura para el porvenir. Al presente le correspondía contribuir al estímulo de la escritura puesto que el periódico [El Mosaico] es el que está destinado a hacer aco-

pio de materiales literarios para el porvenir de nuestras letras. Dicha acción se convertía a la vez en propósito nacional al corresponder a los suscriptores hacer posible la escritura del pasado, la conciencia de una tradición, para determinar de este modo el futuro. (Acosta, 1997, p. 110)
}

El Museo hace parte entonces de una serie de proyectos de Vergara (conformación de una bibliografía granadina, impulso y difusión de la producción de nuevos escritos de autores granadinos, creación de una Biblioteca Granadina a partir de la edición de obras que conformaran una colección nacional) que confluyeron en la construcción de un sentido nacional, y que a la vez generaba nuevos horizontes de expectativas en los grupos lectores. Un accionar configurado en el presente, donde se activa el pasado y el futuro en conjunto: se instaura así una noción de patrimonio desde lo literario.

\section{CONCLUSIONES}

En la modernidad se configura el encuentro del coleccionismo con el museo, ello introduce a este último en el campo de lo visual, lo que posibilita su existencia actual. La observación propia de la curiosidad científica se hace tangible en la escritura, que con principios coleccionistas continúa la empresa de clasificación de la realidad. Es en este contexto que el museo impreso procura, en un primer estadio, el orden y desciframiento del mundo, posteriormente, con principios edificantes, moldear el cuerpo social. Particularmente en el contexto latinoamericano, la actividad coleccionista, sumada al artefacto escritural, toma en algunos casos un carácter de política estatal, conformando órganos de difusión del conocimiento científico como apoyo a los propósitos políticos, económicos y sociales del gobierno, dentro del contexto de conformación de nación. Particularmente en el Museo de cuadros de costumbres y variedades se procura la construcción de una cultura nacional. Esta publicación, con una orientación federalista y un carácter literario, recoge las características geográficas y el carácter de sus gentes.

En cuanto género literario, el carácter descriptivo de los cuadros de costumbres recrea una imagen que resalta los rasgos pintorescos y particulares, pero a la vez los elementos comunes que configurar una noción de comunidad. Así mismo, su vinculación con las publicaciones seriadas (periódico El Mosaico) y su sistema de distribución y relación con los lectores, hace del Museo de cuadros de costumbres y variedades otro vehículo para el reconocimiento de la joven nación, impulsando su progreso mediante el apoyo a la inmigración.

Entonces, del Museum Cartaceo al Museo de cuadros de costumbres y variedades hay, 
pues, una distancia que va más allá de lo geográfico y lo temporal. Museos como el Cartaceo están compuestos principalmente por imágenes, y de hecho, sustentan su valor en la posibilidad de otorgar una colección "portátil" y personal de elementos que difícilmente se podrían presenciar juntos en otras instancias; por su parte, el Museo de cuadros de costumbres y variedades está compuesto por texto, y solo venía acompañado por unas cuantas ilustraciones realizadas a partir de las narraciones, pero que no eran indispensables dentro de la lectura. Sin embargo, la diferencia no radica en esto, en cuanto a que por su alto nivel de descripción, y a la presencia de figuras literarias como la metáfora, el símil y la prosopopeya, es posible considerar los textos como imágenes en sí mismas, de esa "fisionomía moral" que menciona Marroquín, imágenes que adquieren sentido como conjunto.

La diferencia radica en la orientación de la mirada, pues aunque ambos tipos de museo escogen a su observador/lector, la colección del Museo de cuadros de costumbres y variedades se enmarca, así como otras iniciativas propias del siglo XIX en Sur y Centroamérica, en las necesidades propias del nacionalismo imperante del momento. De allí que el visitante lector de este Museo se configure como el extranjero o el colombiano que debe saber cuáles son las características que constituyen la identidad de la nueva nación. Aunque ya no podemos hablar de curiosidad científica propiamente dicha, tampoco se debe desconocer el precedente de la Comisión Corográfica y la posibilidad de caracterizar tipos humanos, que permanece en los cuadros de costumbres publicados en el periódico El Mosaico, y que se enfatizan en el Museo. Es precisamente algo particular del Museo de cuadros de costumbres y variedades la doble curaduría que le dio origen: El Mosaico, dentro de su variedad, ya implicaba un proceso de selección de textos antes de pasar por la imprenta. De este proceso, como narra Vergara y Vergara en el prólogo, se seleccionaron los mejores cuadros de costumbres, probablemente con el objetivo de resaltar aún más los cuadros de tipos humanos insertos en paisajes cuya descripción configura gráficamente una idea unificada de nación.

La valoración del patrimonio nacional presentado en los volúmenes del Museo se enriquece tanto por la apariencia de acumulación como por las posibilidades que ofrece la narración para construir un discurso. Durante el siglo XIX,

Al parecer, la producción de un patrimonio en el área de la cultura funcionaba como soporte imaginario de identidades que se estaban forjando. Por ello, la ficción de abundancia, del espesor, de la antigüedad. Y al respecto, muy particularmente los países hispanoamericanos, sensibilizados por innumerables vacíos después de sus respectivos procesos independentistas, sintieron con especial ahínco la tarea de abocarse, sin escatimar recursos, a la producción de acervos culturales. No es extraño, pues, que tanto las antologías, las historias literarias, las bibliotecas, los museos y las exposiciones universales hayan sido narrativas guiadas bajo el mismo impulso de estructuración de fábulas de identidad para las nuevas naciones que entraban en un cada vez más exigente mercado internacional. (González, 2000, p. 3)

Hay pues de fondo una narrativa historizada, que dirige la mirada en el interior del museo, o del impreso, artefactos ambos del campo visual de la escritura. En el caso del museo impreso, podemos decir que más que una mezcla de las dos unidades anteriores, constituye un tercer lugar que alegoriza, en el contexto propio de la escritura y la imprenta, la habilidad del museo "para insertarse en un amplio rango de prácticas discursivas" (Morales, p. 45). Si el catálogo no es un simple registro de objetos, como señalaba Findlen, el museo impreso 
tampoco puede designarse de esta manera. La recontextualización del objeto presente en el museo impreso termina seleccionando a su propio observador, en este caso un lector que posee el código escritural determinado por la historicidad del momento.

\section{NOTAS}

1 Como la definición del Consejo Internacional de Museos (ICOM) "Un museo es una institución permanente, sin fines de lucro, al servicio de la sociedad y abierta al público, que adquiere, conserva, estudia, expone y difunde el patrimonio material e inmaterial de la humanidad con fines de estudio, educación y recreo" ICOM. "Definición de museo". [En línea] http://icom.museum/quienes-somos/la-vision/definicion-del-museo/L/1.html (Acceso: 25 de junio de 2015).

2 El museion puede entenderse de dos maneras. En primer lugar, servía para designar tanto a la colina de Atenas donde tenían las nueve musas, hijas de Zeus y Mnemosyne (la memoria), su morada, así como, según Corominas, a algunas grutas artificiales con carácter decorativo, adornadas con musgo, conchas y pequeñas piedras, y que se instalaban en los jardines de las villas griegas. En segundo lugar, en Roma se utilizaba el término museion para designar determinados lugares donde los sabios se reunían a discutir en torno a la filosofía, siendo el más conocido el museion de Alejandría. En el siglo III a.C., Ptolomeo I Soter erige el Museion y la Biblioteca Real, que formaban parte de la Basileia, zona de palacios reales. Describiendo el museion, Diógenes Laercio señalaba que este "comprendía un santuario dedicado a las musas, adornado con estatuas de diosas y un busto de Aristóteles, un pequeño patio porticado, otro patio porticado, donde se exhibían las placas grabadas con los mapas de los países explorados hasta entonces, un altar, un jardín, un pórtico y diversas habitaciones. Los estudiosos debían vivir juntos siguiendo normas de familiaridad y amistad a condición de que nadie enajenara o dedicara ninguno de esos bienes para uso privado, sino que los preservaran indivisos, como si de un santuario se tratara" (García Ángeles, 2001, p. 29).

3 En el siglo IV a.C. se construían pequeños santuarios o templos llamados thesaurus, en donde se guardaban valiosas ofrendas de ciudades y príncipes otorgadas a los dioses. En Grecia estos primeros depósitos solo se podían visitar con carácter devocionario. Había en estos templos unos guardianes responsables de las colecciones, y la preocupación por los objetos y por la posible pérdida de alguno de ellos, llevó a realizar una serie de inventarios, como control de piezas. Actualmente este término hace referencia a un sistema de referencias cruzadas para organizar una colección de documentos.

4 "Como otros términos enciclopédicos, era una estructura semántica organizada para incluir 'no sólo la noción de abundancia en sí, sino también el lugar donde se encuentra la abundancia, o más estrictamente, el lugar y sus contenidos'" (Findlen, 2006).

5 Representación de la prosperidad y la afluencia, a partir de un vaso en forma de cuerno, conocido como "cuerno de la abundancia".

6 Lugar donde se han depositado objetos preciosos, ya sea en un palacio o en una iglesia.

7 "A partir del siglo XVI el libro impreso irá tomando una fisionomía propia que básicamente ha perdurado hasta hoy. Las letras se reducen a las empleadas actualmente; los caracteres redondos y los cursivos, desapareciendo el sistema de abreviaturas y signos especiales típico de las escrituras manuscritas medievales. En la segunda mitad del siglo XVI se generalizan las portadas, que pueden contener no solo los datos de identificación bibliográfica como título, autor, lugar, editor y fecha, sino otras referencias, como dedicatorias, títulos y dignidades del autor, etc. (Tagle, 2007, p. 164)

8 "It represents one of the most significant attempts ever made before the age of photography to embrace all human knowledge in visual form" (The Warburg Institute). "Representa uno de los intentos más importantes que se han hecho antes de la era de la fotografía de aprehender todo el conocimiento humano en forma visual" (Traducción de la autora).

9 "The image of the museum proffered in the pages of the "printed museum" was not so much that of a site of knowledge or even of power as with was simply, and more tangibly, a site of moralization. The museum was a school of morality, a direct response to one of the major cultural goals of the century, particularly the idea 
of honor that flourished under the Second Empire. Among the Works reproduced by the "museums", family portraits and genre scenes largely predominated" (Traducción de la autora).

10 Editado por Gaspar y Roig, fundado y dirigido por Nemesio Fernández Cuesta y Picatoste, comenzó con periodicidad quincenal el 15 de enero de 1857 y luego pasó a semanario. En el subtítulo se indicaban en detalle los contenidos: "Periódico de Ciencias, Literatura, Artes, Industria y Conocimientos útiles, ilustrado por los mejores artistas españoles." El formato era folio mayor, con una media de cuatrocientas páginas por año. (Sánchez, 2008, p. 40)

11 "The cultural press in particular eschewed the overt polemics of feuding newspapers in an attempt to foster civic and intellectual homogeneity. The editors professed to subscribe to an integrative and consensual model of cultural transmission which was intended to inculcate similar values in its readers" (Traducción de la autora).

12 "...the implicit parallels to a national museum exhibit, the box-like portable diorama, a Kunstkammer" (Traducción de la autora).

13 Ambición que también proclamaron otros políticos de la época, pero que al parecer solo quedaba como recurso retórico de apertura.

14 Aunque es necesario señalar que no se especifica lo que la autora considera "curiosidad novelesca".

15 Carmen Elisa Acosta señala, por ejemplo, la inclusión del lector como parte activa del desarrollo del cuadro, se le ubica dentro del paisaje por medio de diversas llamadas por parte del autor. Esto, según Acosta, conduce a la adecuación de un lector pertinente para el texto.

16 Existen algunas referencias a la lectura pública de los periódicos, lo que permite suponer el acceso a la información por parte de un público analfabeta; sin embargo, debido a la falta de cifras al respecto resulta complejo hacer un aproximado del porcentaje de la población que seguía con regularidad las publicaciones, y mucho más aún, resulta imposible estimar el valor o la incidencia de los textos en el juicio y las decisiones del público no especializado.

17 Se refiere al título inicial de la obra, Los granadinos pintados por sí mismos, cuando ya la República de Nueva Granada había cambiado de nombre a Confederación Granadina. Además, es importante señalar que con este título se quiso emular una publicación madrileña titulada Los españoles pintados por sí mismos, editada en 1843. También en España se publicó Los valencianos pintados por sí mismos. En Latinoamérica, por su parte, se publican Las habaneras pintadas por sí mismas en miniaturas (1847), Los cubanos pintados por sí mismos (1852) y Los mexicanos pintados por sí mismos (1855). En estas colecciones los artículos también se ilustran con grabados.

18 Dueño de la imprenta que da a luz los dos primeros volúmenes del Museo.

\section{REFERENCIAS}

Acosta, Carmen Elisa. Lectores, lecturas y leídas. Historia de una seducción en el siglo XIX. Bogotá: ICFES, 1997.

Caicedo Rojas, José. “El Mosaico”. El Mosaico, núm. 33, agosto 22. Bogotá, 1860.

Certeau, Michel de. "La economía escrituraria". La invención de lo cotidiano I. Artes de hacer. México: Universidad Iberoamericana, Departamento de Historia, 2000.

Cuvardic García, Dorde. "La construcción de tipos sociales en el costumbrismo latinoamericano". Filología y Lingüística XXXIV (1), 2008: 37-51.

Findlen, Paula. "The Museum. Its Classical Etimology and Renaissance Genealogy". En Museum Studies. An Anthology of Contexts, ed. Bettina Messias Carbonell. Oxford: Blackwell, 2004. 23-50.

Findlen, Paula, "Localizando el museo". En Producciones de sentido. El uso de las fuentes en la historia cultural, 2 por Valentina Torres Septién. México: UIA, 2006.

García Ángeles, Héctor. "Fecha de destrucción de la Biblioteca de Alejandría". Liber: Revista de 
Bibliotecología. Nueva Época, vol. 3, núm. 3 (julio-septiembre 2001): 27-30.

Georgel, Chantal. "The Museum as Metaphor in Nineteenth-Century France." En Museum Culture. eds. Daniel Sherman e Irit Rogoff, Minneapolis: Universidad de Minnesota, 1994. 113-122.

González Stephan, Beatriz. "Coleccionar y exhibir. La construcción de patrimonios nacionales". Hispamérica, Año 29, núm. 86 (agosto, 2000): 3-17.

Gordillo Restrepo, Andrés. “El Mosaico (1858-1872): nacionalismo, elites y cultura en la segunda mitad del siglo XIX." Fronteras de la historia, año/vol. 8. Bogotá: Ministerio de Cultura, 2003. 17-66.

Guhl Corpas, Andrés Ernesto. "La Comisión Corográfica y su lugar en la geografía moderna y contemporánea". En Geografía física y política de la Confederación Granadina (Estado de Antioquia), vol. 4. Medellín: Centro De Publicaciones Universidad Eafit, 2005. 27-41.

Hernández Hernández, Francisca. Planteamientos teóricos de la museología. España: Ed. Trea, 2006.

ICOM. “Definición de museo". [En línea] http://icom.museum/quienes-somos/la-vision/definiciondel-museo/L/1.html (Acceso: 25 de junio de 2015).

Marroquín, José Manuel. “El “Museo de cuadros de costumbres y variedades". La Caridad. Bogotá: vol. 3, núm. 1, agosto 10 de 1886.

Morales, Luis Gerardo. "Museo y grafía: observación y lectura de los objetos". Historia y Grafía, Revista semestral Departamento de Historia, núm. 13. México: Universidad Iberoamericana, 1999: 225-253.

Morales, Luis Gerardo. "La "crisis" de los Museos de Historia". Museología e historia: un campo del conocimiento / ICOFOM. Argentina: Museo Nacional Estancia Jesuítica de Alta Gracia y Casa del Virrey Liniers, 2006. [En línea] http://www.museoliniers.org.ar/museologia/conferencias/ GerardoMoralesMoreno-LaCrisisdelosmuseosdehistoria.pdf (Acceso: 26 de junio de 2015).

Morales, Luis Gerardo. "Límites narrativos de los museos de historia". Alteridades vol. 19, núm. 37 (enero-junio, 2009): 43-56.

Musée d' Orsay. "The printed museum". [En línea] http://www.musee-orsay.fr/en/events/exhibitions/ archives/archives/browse/23/article/le-musee-imprime-4126.html (Acceso: 25 de junio de 2015).

Ong, Walter J. Oralidad y escritura. Tecnologías de la palabra. México: Fondo de Cultura Económica, 1987.

Sánchez Vigil, Juan Miguel. Revistas ilustradas en España. Del Romanticismo a la Guerra Civil. España: Ed. Trea, 2008.

Segre, Erica. "The Development of Costumbrista: Iconography and Nation-building Strategies in Literary Periodicals of the Mid-Nineteenth Century". Intersected identities: strategies of visualization in nineteenth - and twentieth - century Mexican cultura. United States: Berghahn Books, 2007.

Tagle, Matilde. Historia del libro: texto e imágenes. Buenos Aires: Alfagrama Ediciones, 2007.

The Walburg Institute. "The paper museum of Cassiano dal Pozzo a catalogue raisonné" [En línea] http://warburg.sas.ac.uk/research/projects/cassiano/ (Acceso: 25 de junio de 2015)

Vergara y Vergara, José María. El Mosaico. Bogotá: núm. 1, 1858.

Von der Walde, Erna. "El cuadro de costumbres y el proyecto hispano-católico de unificación nacional en Colombia". ARBOR Ciencia, Pensamiento y Cultura, CLXXXIII, núm. 724 (marzoabril, 2007): 243-253. 


\section{Cómo citar este artículo:}

Galindo Cruz, Diana. "El museo (en el) impreso. Un acercamiento al Museo de cuadros de costumbres y variedades". Cuadernos de Música, Artes Visuales y Artes Escénicas, 10(2), 107-130, 2015. http://dx.doi.org/10.11144/ Javeriana.mavae10-2.miam 